
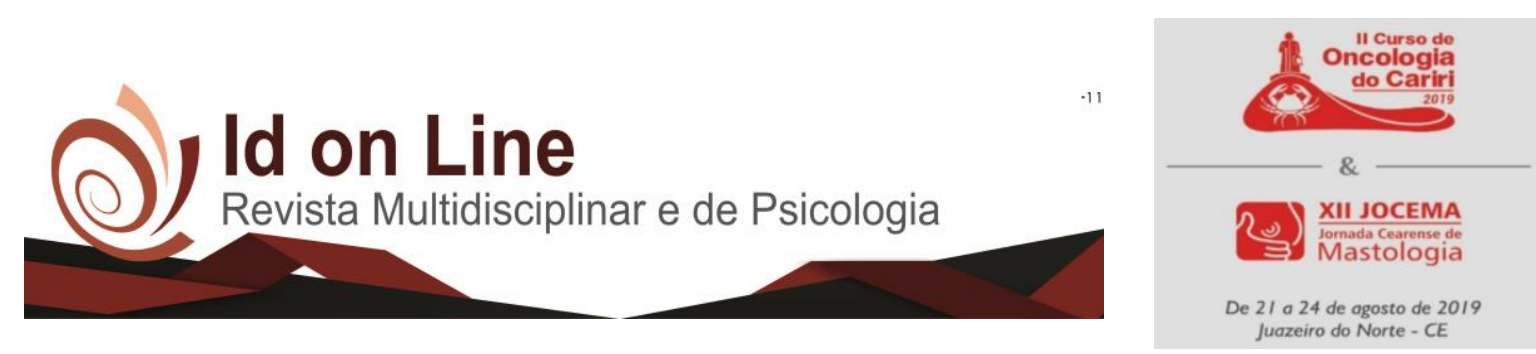

DOI: 10.14295/idonline.v13i46.2007

Resumo

\title{
DIETOTERAPIA E CUIDADOS PALIATIVOS EM PACIENTES ONCOLÓGICOS
}

\author{
Suanam Altair Tavares de Menezes ${ }^{1}$, Ana Clara Lacerda Cervantes de Carvalho ${ }^{1}$, Karina Morais Borges ${ }^{2}$, \\ Renata Andriola Colares ${ }^{2}$, Victor Pinheiro Gomes e Albuquerque ${ }^{2}$, Mariana Machado Bueno ${ }^{3}$
}

Introdução: O câncer vem destacando-se por sua alta taxa de desenvolvimento, segundo dados epidemiológicos divulgados pelo Instituto Nacional de Câncer no Brasil em 2018, a incidência foi de 582.590 e o numero de óbitos chegou a 218.640. Cuidados paliativos (CP) em oncologia sugerem proporcionar um suporte global ao paciente, a fim de amenizar sintomas e melhorar a qualidade de vida (QV) daqueles em que o tratamento já não é mais uma opção de cura. Objetivos: O objetivo do estudo foi identificar os principais aspectos e condutas do cuidado paliativo nutricional no tratamento oncológico. Método: Este estudo trata-se de uma revisão sistemática sem metanálise, realizada em agosto de 2019, na qual foram consultadas as bases de dados SCIELO e PUBMED, utilizando os descritores associados ao operador booleano (AND): Dieta. Neoplasias. Cuidados paliativos. Foram inclusos: artigos dos últimos 12 anos, artigos em inglês e português. Foram excluídos: artigos repetidos e monografias. Resultados: Foram encontrados ao todo 66 estudos, após aplicação do filtro restaram 10 e mediante leitura dos mesmos 6 enquadraram-se com o tema proposto. A terapia nutricional em $\mathrm{CP}$ tem que considerar a incapacidade do paciente em deglutir, digerir e absorver nutrientes, promover conforto, prazer, melhor QV e controlar os sintomas nutricionais relacionados à progressão da doença (exemplo: anorexia, náuseas, obstipação, xerostomia, caquexia, diarréia, inapetência e outros). Espera-se assim prolongar a perda da auto-suficiência garantindo uma sobrevida com dignidade ao individuo. Quando possível, deve-se favorecer alimentação por via oral (VO), devendo ser ofertados alimentos preferidos do paciente, caso a alimentação e a hidratação por VO sejam impossíveis ou insuficientes para atingir as necessidades nutricionais, deve-se então considerar via enteral ou via parenteral, desde que não sejam medidas fúteis, desconfortáveis, respeitem os princípios éticos e decisão do paciente e família, contribua com uma melhor QV e maior sobrevida. Conclusão: A alimentação é importante em $\mathrm{CP}$, podendo auxiliar o paciente oncológico nos âmbitos físico e mental. Contudo, dificilmente a alimentação será capaz de exercer sua função de restaurar uma condição nutricional adequada. Nesse estágio, a intercessão da equipe multidisciplinar e em especial o nutricionista é ponderar sobre as necessidades e desejos do paciente e família, essenciais para que se controlem sintomas indesejáveis e assegurar prazer e alívio.

Palavras-chave: Dieta. Neoplasias. Cuidados paliativos.

\footnotetext{
${ }^{1}$ Discente do curso de Nutrição, na Faculdade de Juazeiro do Norte - FJN, Juazeiro do Norte, CE, Brasil.

${ }^{2}$ Nutricionista, Docente do curso de Nutrição, na Faculdade de Juazeiro do Norte - FJN, Juazeiro do Norte, CE, Brasil

${ }^{3}$ Orientadora, Nutricionista, Docente do curso de Nutrição, na Faculdade de Juazeiro do Norte - FJN, Juazeiro do Norte, CE, Brasil

Autor correspondente: sussu.tavares@ hotmail.com.
} 


\section{Referencias}

ANDRADE, J. S; ALMEIDA, M. M; PINHO-REIS, C. Principios bioeticos e nutrição em cuidados paliativos. Acta Port Nutr, Porto, n. 9, p. 12-16, 2017.

BENARROZ, M. O.; FAILlACE, G. B. D.; BARBOSA, L. A.; Bioética e nutrição em cuidados paliativos oncológicos em adultos. Cadernos de Saúde Pública. v. 25, p. 1875-1882, 2009.

CORRÊA, P. H.; SHIBUYA, E. Administração da terapia nutricional em cuidados paliativos. Revista Brasileira de Cancerologia. v. 53, n. 3, p. 317-323, 2007.

INCA. Coordenação de Prevenção e Vigilância / Divisão de vigilância e analise de situação. Estimativa 2018: incidência de câncer no Brasil e índice de mortalidade / Instituto Nacional de Câncer José Alencar Gomes da Silva. Coordenação de Prevenção e Vigilância. - INCA, 2019. Disponível em < https://www.inca.gov.br/numeros-de-cancer>. Acesso em: 25/07/2019.

MORAIS, S. R. D.; BEZERRA, A. N.; CARVALHO, N. S; VIANA, A. C. C. Nutrição, qualidade de vida e cuidados paliativos: uma revisão integrativa. Revista Dor. v. 17, n. 2, p. 136-140, 2016. PINHO-REIS, C. Suporte Nutricional em Cuidados Paliativos. Nutrícias, Porto, n. 15, p. 24-27, 2012 .

PINTO, I. F.; CAMPOS, C. J. G. Os Nutricionistas e os Cuidados paliativos. Acta Portuguesa de Nutrição, n. 7, p. 40-43, 2016. 